\title{
Nickel-titanium alloys: A systematic review
}

Marcelo do Amaral Ferreira', Marco Antônio Luersen², Paulo César Borges²

Objective: A systematic review on nickel-titanium wires was performed. The strategy was focused on EntrezPubMed-OLDMEDLINE, Scopus and BioMed Central from 1963 to 2008.

Methods: Papers in English and French describing the behavior of these wires and laboratorial methods to identify crystalline transformation were considered. A total of 29 papers were selected.

Results: Nickel-titanium wires show exceptional features in terms of elasticity and shape memory effects. However, clinical applications request a deeper knowledge of these properties in order to allow the professional to use them in a rational manner. In addition, the necessary information regarding each alloy often does not correspond to the information given by the manufacturer. Many alloys called "superelastic" do not present this effect; they just behave as less stiff alloys, with a larger springback if compared to the stainless steel wires.

Conclusions: Laboratory tests are the only means to observe the real behavior of these materials, including temperature transition range (TTR) and applied tensions. However, it is also possible to determine in which TTR these alloys change the crystalline structure.

Keywords: Nickel-titanium wires. Thermoelasticity. Shape memory alloys. Superelasticity.

${ }^{1} \mathrm{PhD}$ in Sciences, UTFPR.

${ }^{2} \mathrm{PhD}$ and Professor, DAMEC-UTFPR.

» The authors report no commercial, proprietary or financial interest in the products or companies described in this article.

» Patients displayed in this article previously approved the use of their facial and intraoral photographs.
How to cite this article: Ferreira MA, Luersen MA, Borges PC. Nickel-titanium alloys: A systematic review. Dental Press J Orthod. 2012 May-June;17(3):71-82.

Submitted: January 24, 2009 - Revised and accepted: February 9, 2010

Contact address: Marcelo do Amaral Ferreira

R. Dr. Corrêa Coelho, 744, ap. 203 - Jardim Botânico - Curitiba/PR - Brazil

Zip code: 80.210-350 - E-mail: regunteriato@yahoo.com.br 


\section{INTRODUCTION}

Metallic alloys that tend to return to the original shape after large deflections have been appreciated since the $50 \mathrm{~s}$. They have been studied not only for their use in Aeronautical Engineering, because of their sufficient ductility, ${ }^{22}$ but also in Medicine in the development of prostheses that replace long bones and in the study of surfaces and biofilms. ${ }^{14}$ In Orthodontics, these materials are used in archwires for the alignment of teeth, in the initial stages of treatment, when large deflection is necessary and also because they present a low modulus of elasticity (E) and excellent springback when compared to other alloys (Fig 1). Table 1 shows the nature of metallic alloys used in Orthodontics and their mechanical properties.

There is great variability in the amount of stored energy in same cross-section nickel-titanium alloys, available from different manufacturers. Many of them are commercialized as shape memory alloys, while others do not even show the effect of superelasticity ${ }^{17}$ and present characteristics of martensitic-stabilized alloys as the alloys originally known as Nitinol (Unitek, Monrovia, CA, USA). Some studies $^{4,10,11,15,24}$ question the comparative methods by means of laboratory tests which do not correspond to the variability of clinical situations found.

The aim of this paper is to discuss the behavior of the mechanical properties of these alloys according to literature.

\section{Characteristics and current status of nickel-titanium alloys}

Nickel-titanium alloys were initially studied in laboratories by physicists in the beginning of the $60 \mathrm{~s}^{8}$ and later developed for clinical use. ${ }^{1}$ Due to the development of these alloys, new options have emerged such as the nickel-titanium arch wires with superelasticity and thermoelastic properties.

Initially, nickel-titanium wires presented greater flexibility when compared to other alloys, such as stainless steel, cobalt-chromium and titanium-molybdenum alloys (TMA). Nickel-titanium alloys, known by their brand name Nitinol (55\% $\mathrm{Ni} ; 45 \% \mathrm{Ti}$ ), are produced through industrial processes that characterize them by stabilized martensite, due to cold work. ${ }^{1}$ Effectively, they do not present the so-called shape memory effect or the superelasticity effect. They just present low modulus of elasticity (E) and large springback, in other words, wires made of these alloys are flexible and show linear behavior (Fig 2).

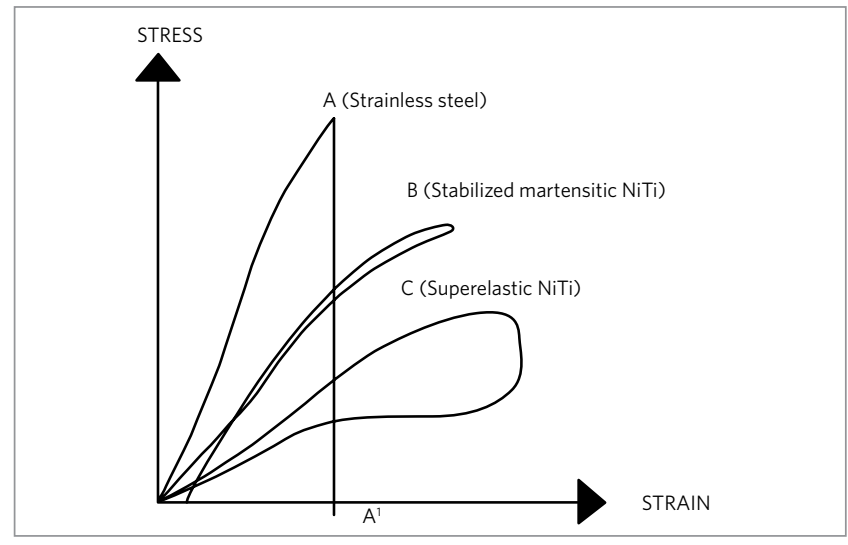

Figure 1 - Stress $x$ Strain diagram. A, B and C wires present different stiffness. A represents stainless steel behavior; $B$ represents stabilized martensitic wire (ex. nitinol) and $C$ represents superelastic wire.

Table 1 - Wire material, Elastic limit ( $\sigma e)$ and Elasticity modulus (E).

\begin{tabular}{ccc} 
Wire material & $\begin{array}{c}\text { Elastic limit } \\
(\mathbf{M P a})\end{array}$ & $\begin{array}{c}\text { Elasticity modulus (E) } \\
\text { (GPa) }\end{array}$ \\
\hline Stainless steel & $1720 / 1543-1966$ & 193 \\
Titanium molybdenum & $12401380 / 769-1254$ & $65-100$ \\
Cobalt-chromium & 1792 & 193 \\
Nickel-titanium & 1650 & 33 \\
\hline
\end{tabular}

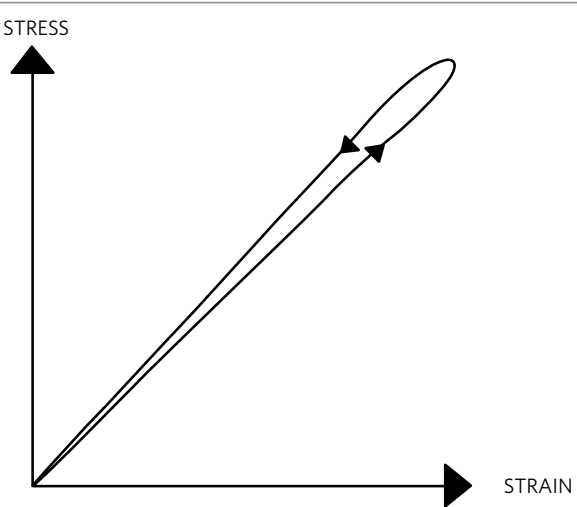

Figure 2 - Stress $x$ strain graph. Analyzing the graph, this could be a martensitic alloy-stabilized, as well as a superelastic alloy, the deformation of which was not sufficient to cause the effect of superelasticity (plateaus). There are superelastic alloys whose Af is so low that it is useless for clinical use because does not suffer crystal change with the forces commonly used in the daily clinic. 
Nowadays, nickel-titanium alloys known as martensitic-stabilized (Nitinol), austenitic active and martensitic active alloys ${ }^{10,26}$ are available. Austenitic active and martensitic active alloys present different rigidity depending on temperature and as show the thermoelastic effect or shape memory. For the martensitic-stabilized alloys, it is expected only good elasticity effect, thus having good springback; however, they can be deformed permanently, if a certain limit is exceeded or due to long time remaining in the mouth (moderate or severe crowding, for example). Superelasticity or shape memory effects should not be expected. Austenitic active alloys should present the effect of superelasticity (also known as pseudoelasticity, ${ }^{26}$ confirmed by curve with plateaus, which are not possible in martensitic-stabilized alloys). Many NiTi alloys are described as binary, in other words, they are characterized as presenting two phases, one NiTi matrix phase and a precipitation phase $\mathrm{Ni}_{3} \mathrm{Ti}_{4}{ }^{12}$

Martensitic alloys are characterized as ductile and plastically deformable, while austenitic alloys are stiffer and not plastically deformable ${ }^{3}$. In a more simplistic way, it might be stated that austenitic active wires are more flexible and have good springback at room temperature; and if a certain tension (force) is applied upon them, small areas of martensitic crystalline structure might be formed, making them less stiff in these areas and, consequently, easier to fit in a slot. In other words, little islands of crystalline martensitic structure are formed in a predominantly austenitic body. On the other hand, martensitic active wires show, at room temperature, very poor resistance to stress and discrete springback, so that they seem to accept a certain bend and, after removing it, the wire moves discretely toward the original shape, but without success because of the force decay. However, as they receive heat from the mouth, they initiate an austenitic crystalline alteration, becoming more resistant to stress and regaining their initial shape, confirming the shape memory effect. Once the heat is removed or the wire is cooled down, they present their initial characteristic, having predominantly a martensitic crystalline structure. In this alloy exist a mixed or rhombohedral phase " $R$ " at room temperature that coexist with austenite and martensite structure.

\section{MATERIAL AND METHODS}

Articles related to the topic were researched (Entrez-PubMed - U.S. National Library of Medicine e BioMed Central) from 1963 to 2008. The words NiTi wires were accessed and 375 occurrences were found. Among these occurrences, we have selected articles that contained information about tension tests, torsion tests, bending tests or other methods for verifying the behavior and crystallography of nickel-titanium alloys. A textbook on Biomedical Engineering was also used as source of information.

\section{DISCUSSION}

In graphic terms, the crystalline transformation of the austenitic active nickel-titanium alloys might be demonstrated by a straight line with a certain inclination, indicative of its degree of rigidity (E), which after a certain magnitude of applied bend, goes through a crystalline transformation (molecular arrangement), changing from austenite to martensite, represented by plateau A (Fig 3), indicating that regardless of more wire deformation, the tension is practically the same. In other words, the tension is constant along the resulting deformation. After the tension is removed (for each tension applied there is a corresponding force), the curve shows a decrease at its tension magnitude, with a new inclination and, consequently, new rigidity, until a new plateau $\mathrm{B}$ is formed, though at a smaller tension magnitude.

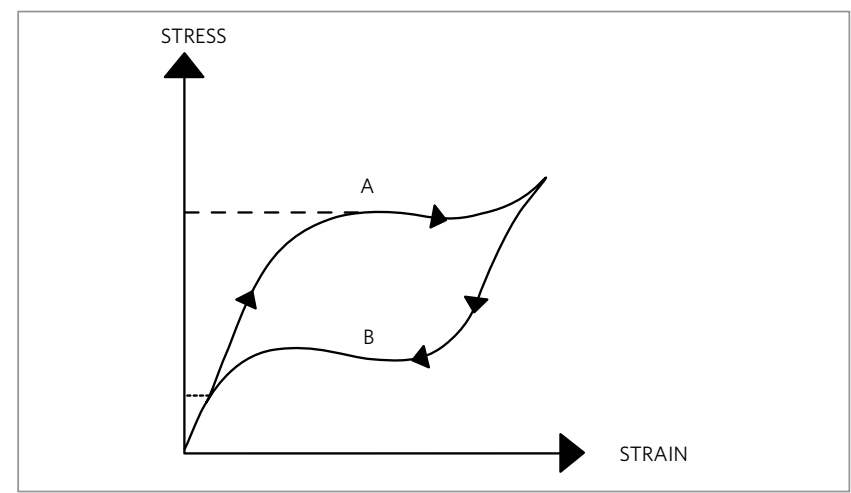

Figure 3 - Stress $x$ strain graph. Typical curve for a superelastic alloy, forming plateaus. The plateau A represents the crystalline martensitic change at a certain level of tension, while plateau $B$ represents a new martensitic transformation, but at a lower voltage level. Between $A$ and $B$ there is new formation of austenite with stiffness equal to that prior to the plateau $A$. The plateau $A$ is formed due to the stress-induced martensite, due to metal arc be attached to the slot brackets, while the plateau $B$ is formed due to the reduction of tension (motion toward the dental arch alignment). 
The difference between the plateaus is explained by the phenomenon of hysteresis (loss of energy because of crystalline alteration). After the tension is removed, reverse crystalline transformation from martensite to austenite occurs. This graph describes the superelasticity effect, not observed regarding the martensitic-stabilized alloys, such as Nitinol.

The effect of superelasticity introduces a new property of metallic alloys, characterized by the appearance of martensitic crystalline structures in an austenitic structure, after the use of a certain stress. This generates areas of stress-induced martensite (SIM) which takes place in the parts of the metallic wire tied to the brackets of the most unaligned teeth; however, as the teeth get aligned, these areas of induced martensite disappear and are replaced by austenite, since the induced martensite areas are very unstable. Depending on the manufacturer, the nickel-titanium wires have a temperature range in which it is possible to observe the effects of crystalline alteration. This range of temperature is known as transition temperature range (TTR) and it presents final and initial limits, denominated - for the austenitic crystalline structure - as final austenite (Af) and initial austenite (As); thus, in Af temperature the maximum elasticity of these alloys takes place, while in As temperature weak elasticity is observed. For the martensitic active alloys there is also a temperature range in which these phenomena take place; thus, Mf and Ms indicate a higher level of martensite and lower level of martensite, respectively. Many of these wires are sensitive to applied tension and to temperature. Focus is on the concept of crystalline TTR, the temperature range in which some crystalline transformation might take place, and the austenitic final temperature was defined (Af), in which the alloy reveals a high stiffness phase, as well as the final martensitic temperature (Mf), in which the alloy reveals a low stiffness phase.

Figure 4 shows the characteristic curve of shape memory for the wires, Ms and Mf represent the temperatures where crystallographic martensitic alteration begins and where it ends, respectively. On the other hand, As and Af temperatures represent where the austenitic alteration begins and ends, respectively. Therefore, there is martensitic transformation between Ms and Mf temperatures and the wire might present characteristics of plasticity; on the way to As temperature, the wire begins to show greater rigidity. It might be stated that superelastic wires may return to the initial shape when a force is abruptly applied and when a force of considerable magnitude is removed. In the martensitic stage, two effects are noticed: In the first one, after some initial deformation, the crystallographic variants that might be found in 24 shapes of coexisting martensite and after the removal of force, these variants reorganize themselves in their initial positions and the wire returns to its original shape. In the second case, the nickel-titanium wire shaped in the austenitic state is cooled down until it reaches the martensitic state. If during the process the material is deformed, it returns to its initial shape after heating and this phenomenon is called shape memory effect. ${ }^{16}$ Austenitic structures are face-centred cubic $\alpha$ phase while martensitic structures correspond to body-centred cubic $\beta$ phase. They have exactly the same chemical constitution, but because of their different crystallographic structure, they do not exhibit the same mechanical behavior. ${ }^{2}$ Between iM and fA there are initial levels of each transformation where the alloys begin to show some crystalline transformation. The highest temperature in which it is still possible to find the formation of martensite is called Md. ${ }^{19}$

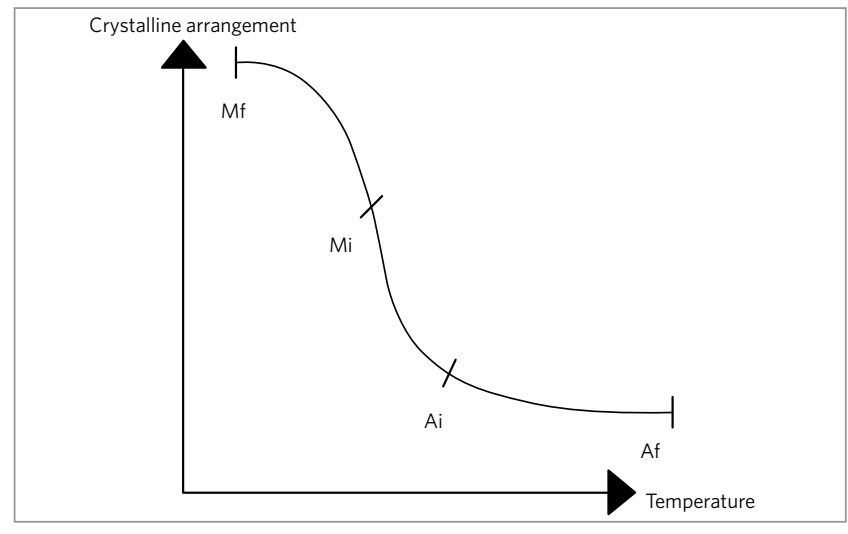

Figure 4 - Austenitic-martensitic transformation of crystalline arrangement vs. temperature. 
Table 2 - Reviewed literature, authors, wire material and applied tests.
Authors
NiTi nature
Test / Method

Nakano et $\mathrm{al}^{24}$

Augereau et $\mathrm{al}^{2}$

Parvizi, Rock ${ }^{25}$

Santoro, Beshers ${ }^{27}$

Buehler, Gilfrich, Wiley ${ }^{8}$

Andreasen, Hilleman

Uchil $^{28}$

Burstone, Quin, Norton

Miura et $\mathrm{al}^{21}$

Gurgel et al ${ }^{15}$

Filleul, Constant ${ }^{11}$

Bradley $^{5}$

Brantley et $\mathrm{al}^{6}$

Brantley et $\mathrm{al}^{7}$

lijima et al ${ }^{17}$

Filleul, Bourgoin ${ }^{10}$

Fischer-Brandies ${ }^{12}$

Meling, Ǿdegaard ${ }^{18}$

Meling, Ǿdegaard ${ }^{19}$

Meling, Ǿdegaard ${ }^{20}$

Barwart et al ${ }^{4}$

Somsen et $\mathrm{al}^{30}$

Bartzela et $\mathrm{al}^{3}$

Garrek, Jordan ${ }^{13}$

Schneevoigt et al ${ }^{29}$

Muraviev et $\mathrm{al}^{23}$
Superelastic NiTi wires with different cross-sections

Shape memory NiTi (Cu-Zn-Al)

Supereleastic NiTi $0.40 \mathrm{~mm}$ and

$0.40 \times 0.56 \mathrm{~mm}$

Thermoelastic and superelastic NiTi wires $0.017 \times 0.025$-in

NiTi wires

NiTi Wires - stoichiometric composition

Nitinol cold-worked $40 \%$ wire sections of $6 \mathrm{~cm}$

Chinese NiTi (superelastic) 0.016-in

Japanese NiTi (superlastic)

Superelastic NiTi wires $0.017 \times 0.025$-in

$\mathrm{NiTi}$ (superelastic) $0.017 \times 0.025$-in

NiTi wires (superelastic)

NiTi wires (0.016-in, $0.016 \times 0.022$-in and

0.018 -in) superelastic and shape memory

Copper $\mathrm{NiTi}\left(35^{\circ} \mathrm{C}\right), 0.016 \times 0.022$-in

Copper $\mathrm{NiTi}\left(35^{\circ} \mathrm{C}\right)$, Neo-Sentalloy and Nitinol SE $0.016 \mathrm{X}$ 0.022-in

SS, CoCr, NiCr, Titanium-molybdenum

and Nitinol wires

Superelastic NiTi wires: $0.016 \times 0.022$-in,

$0.017 \times 0.025$-in, $0.018 \times 0.025$-in

Superelastic NiTi wires, Nitinol and titanium-molibdenum wires: $0.016 \times 0.022$-in, $0.017 \times 0.025$-in and $0.018 \times 0.025$-in

Superelastic NiTi wires $(0.017 \times 0.025$-in and $0.018 \times 0.025$-in $)$

Superelastic NiTi wires $(0.018 \times 0.025$-in $)$ and thermoelastic wires (Copper NiTi $0.017 \times 0.025-$ in)

NiTi Japanese coils (50 g, $100 \mathrm{~g}, 150 \mathrm{~g}$ and $200 \mathrm{~g}$ )

$\operatorname{NiTi}(51 \%<x<54 \%)$

Thermoelastic NiTi wires 0.016-in, 0.016 x 0.022-in, 0.017 x 0.025 -in and $0.018 \times 0.025$-in

Superelastic NiTi wires $(0.016 \times 0.016$-in, $0.018 \times 0.018$-in and $0.020 \times 0.020$-in)

NiTi coils (different geometries)

Superelastic NiTi wires (0.014-in, 0.016-in, 0.018-in

and 0.020 -in)
Three point bending test

Echography and acoustic microscopy

Three point bending tests

$\left(20^{\circ} \mathrm{C}, 30^{\circ} \mathrm{C}\right.$ and $40^{\circ} \mathrm{C}$ )

Three point bending tests

X-ray diffraction (XRD), tension tests, compression tests

X-ray diffraction, tension tests, compression tests

Dilatometric measurements and electrical resistivity

Torsion tests

Three point bending tests

Torsion tests

Torsion tests and differential scanning calorimetry (DSC)

Differential scanning calorimetry (DSC)

Differential scanning calorimetry (DSC)

Differential scanning calorimetry (DSC) and temperature modulated differential scanning calorimetry (TMDSC)

Torsion tests X-ray diffraction (XRD)

Torsion tests

Bending tests $\left(22^{\circ} \mathrm{C}, 37^{\circ} \mathrm{C}\right.$ and $\left.60^{\circ} \mathrm{C}\right)$

Torsion tests $\left(25^{\circ}\right.$ torsion angle at $\left.37^{\circ} \mathrm{C}\right)$

Torsion tests ( $25^{\circ}$ torsion angle) at $18^{\circ} \mathrm{C}, 27^{\circ} \mathrm{C}, 37^{\circ} \mathrm{C}$ and $40^{\circ} \mathrm{C}$

Torsion tests at $20^{\circ}\left(10^{\circ} \mathrm{C}\right.$ to $\left.80^{\circ} \mathrm{C}\right)$

Differential scanning calorimetry (DSC)

Thermal control, electrical resistivity, X-ray diffraction

Three point bending tests

Three point bending tests at $37^{\circ} \mathrm{C} \pm 5^{\circ} \mathrm{C}$

Compression tests $\left(27^{\circ} \mathrm{C}, 37^{\circ} \mathrm{C}\right.$ and $\left.47^{\circ} \mathrm{C}\right)$

Applied $(0,5 \mathrm{~N}$ to $3,5 \mathrm{~N})$

Mathematical model (large deflections) 
Martensite normally forms at the Ms (martensite start) temperature but can form prematurely above the Ms temperature if stress is present. Below the Ms temperature, deformation occurs by martensitic twinning. Between the Ms temperature and the austenite final Af temperature, the martensite is stress-induced but once induced is stable. ${ }^{19}$ Above the Md temperature, the deformation is due to slip, because martensite can no longer be stress induced. ${ }^{19}$ Table 2 shows the variety of studies developed according to the type of test.

To the effect of crystalline transition within a certain temperature range take place at Af temperature (final austenitic), representing the highest level of occurrence of this crystalline structure, the alloy should be manufactured to respond with good springback for a temperature lower than that of the mouth (e.g. around $27^{\circ} \mathrm{C}$ ), but if it is manufactured to have an $\mathrm{Af}$ of, for instance, $10^{\circ} \mathrm{C}$, the alloy will be predominantly austenitic at $10^{\circ} \mathrm{C}$; thus, if exposed to a $37^{\circ} \mathrm{C}$ temperature, the wire would not be useful, considering that the $37^{\circ} \mathrm{C}-10^{\circ} \mathrm{C}$ range is large and the wire would be too stiff working as a stiff elastic wire, without presenting the effect of superelasticity or, in other words, pseudoelasticity. Moreover, greater stress would be necessary to induce or keep stress induced martensite (SIM) for a longer period in order to produce a prolonged dental movement. It because there is a greater chance to find austenite in the temperature mentioned in the example given. In addition, stress induced martensite (SIM) is highly unstable. However, if produced to have an Af of $27^{\circ} \mathrm{C}$, the gradient would be $37^{\circ} \mathrm{C}-27^{\circ} \mathrm{C}$, therefore, islands of unstable martensite would be present and the wire would show superelasticity. ${ }^{25}$ Concerning a wire produced for an Af of $35^{\circ} \mathrm{C}$, the gradient would be so small that this wire would be recommended for use in adults, because the level of austenite would be weak, or in other words, austenite and martensite stages would coexist. In addition, there is evidence that SIM may alter the crystalline transformation temperature towards higher temperatures, making the return to an austenitic crystalline structure difficult. ${ }^{16,27}$ The temperature gradient will, therefore, modulate the crystalline transformation. Thus, if we confront an arch with a certain Af temperature, the difference between the temperature specified for the arch and the temperature of the buccal cavity is the gradient, and it will determine the degree of transformation. ${ }^{26,27}$ In this way, the arches available as thermoelastic, with TTR (Af) $40^{\circ} \mathrm{C}$, will be less austenitic in their crystalline structure than those with TTR (Af) $27^{\circ} \mathrm{C}$, due to a higher gradient in relation to the temperature of the buccal cavity $\left(37^{\circ} \mathrm{C}\right)$, as exemplified. Arches with higher crystalline TTR have been provided to be used in patients who had a history of periodontal problems because the arches would effectively act only when the patient eat some hot food.

It is necessary to know if the discussed arch presents enough resilience to take the springback to the expected torsional moment during unloading, that is to say, if this arch presents the second plateau at force levels that are not so low, preferably close to the first plateau, meaning lower hysteresis. In other words, it would be important to have an arch that allowed us to obtain martensitic transformation with little stress, and later, due to buccal temperature, the arch would go through austenitic transformation, and that would help the unloading of the torsional moment to take place in a more profitable way, but without much hysteresis (loss of energy due to crystalline alteration). Arches with "higher temperature" will not be effective for the effect of torsional moment; consequently, it would be preferable to choose arches with crystalline TTR from $22^{\circ} \mathrm{C}$ to $27^{\circ} \mathrm{C}$. Stress might interfere upon the mechanical properties of the alloy, as well as upon the TTR, i.e., it might increase the Af of an alloy, or decrease it. Resistivity tests ${ }^{27}$ show that the curve of resistivity gets flatter, indicating that crystalline alteration decreases from one stage to another. The more an elastic alloy is bent to fit in the slot, more Af is increased, consequently a higher temperature will be necessary for superelasticity to take place; higher temperature will be necessary to undo the martensite islands formed during the bending of the wire, and for the alloy to guide the tooth to the end of the elastic work of the arch, meaning that a higher temperature will be needed for the conversion of martensite into austenite (the alloy cannot regain its austenitic stage).

Studies ${ }^{4}$ about the TTR of nickel-titanium Japanese NiTi closed coil springs (Sentalloy, GAC 
International, Bohemia, USA), with different force magnitudes (50 g, $100 \mathrm{~g}, 150 \mathrm{~g}$ and $200 \mathrm{~g}$ ) using differential scanning calorimetry technique (DSC) have concluded that the springs became superelastic when the temperature increased and would no longer be superelastic when the temperature decreased at Mf. Both Mf and As temperatures were below buccal temperature. At room temperature and some degrees below the tested springs showed the superelasticity effect, and that would fit the purposes of orthodontic use, even when considering the alterations of buccal cavity temperature, such as during meals. In this way, for the superelasticity effect to become useful in orthodontics, the transitional crystalline alterations (martensitic-austenitic or austenitic-martensitic), must take place at temperature a little below the mouth temperature.

Sentalloy alloys present a transitional temperature that varies from $8^{\circ} \mathrm{C}(\mathrm{As})$ to $28^{\circ} \mathrm{C}$ (Af) at maximum stress, but when buccal temperature is $36^{\circ} \mathrm{C}$ or $37^{\circ} \mathrm{C}$, they just show the austenitic stage, unless the temperature drops below $28^{\circ} \mathrm{C}$. On the other hand, Copper NiTi $35^{\circ} \mathrm{C}$ alloys (Ormco, Orange, $\mathrm{CA}, \mathrm{USA}$ ) are superelastic at $35^{\circ} \mathrm{C}$ (Af) and only below $7^{\circ} \mathrm{C}$ (As) turn to martensitic; however, with induced stress, the TTR stands between $23^{\circ} \mathrm{C}$ (As) and $41^{\circ} \mathrm{C}$ (Af); consequently, when the temperature is below $23^{\circ} \mathrm{C}$, only the conventional elastic effect takes place, making the alloy return force not meaningful ${ }^{27}$. Figure 5A shows a clinical situation where the nickel-titanium arch does not allow total contact with the bracket slot, meaning that the plateau could not be reached; consequently, it would not be working as superelastic, or it was not possible with such stress to produce crystalline alteration with the formation of martensite in that wire. On the other hand, in situation B (Fig 5B), the arch could fit the slot completely, presumably reaching the plateau, once this wire allowed the crystalline martensitic transformation to take place with the same stress. If the wire is forced into the bracket, as in situation A, stress induced martensite is being produced at a very high force level, which not only is not interesting for clinical application, but also might plastically deform the wire, and consequently the mechanical properties of the alloy, the TTR change and the correspondence between this temperature and the buccal temperature range is lost. Thus, a stage of transformation of austenite into martensite, or vice versa, might be altered and the alloy will not express its characteristics and will behave only as a resilient alloy, elastic with a lower elasticity model. In this way, a clinician might purchase an expensive alloy, without effectively using properties. The alloy will not be able to move the tooth effectively, in other words, the alloy will not reach its final transition temperature (Af) because it was poorly chosen for that clinical situation.

Since the first studies ${ }^{8}$ about nickel-titanium alloys were introduced, the alloy have improved in mechanical properties in order to respond to clinical needs, but laboratory studies have shown that
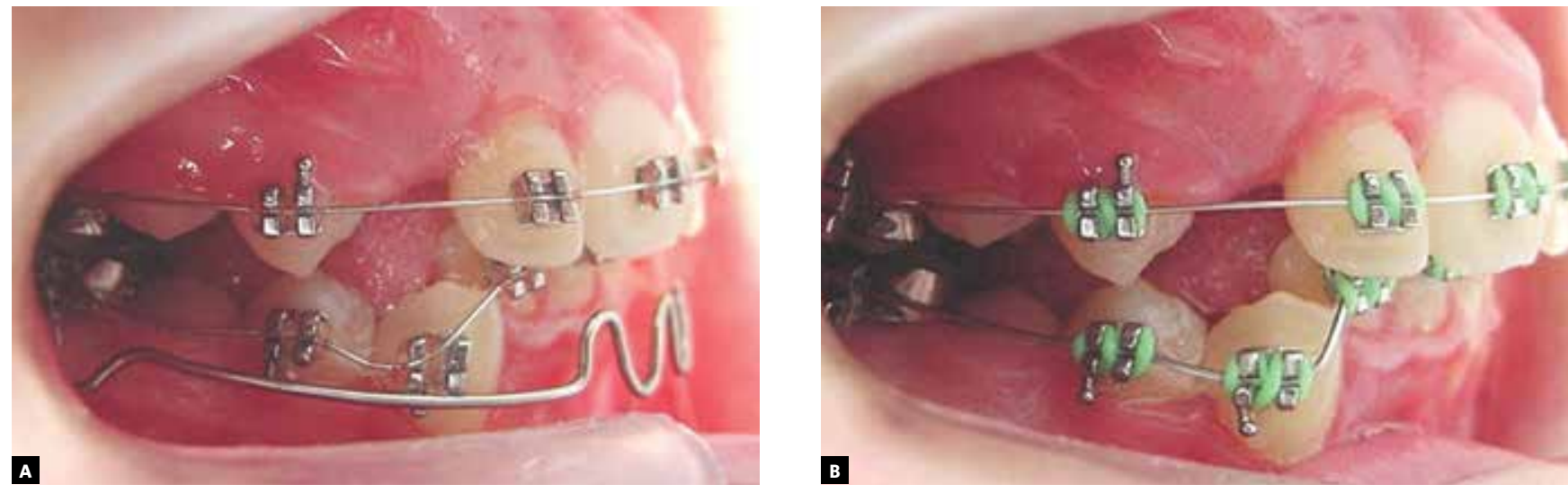

Figure 5 - A) Clinical situation where is not possible to insert a NiTi wire into the bracket slot. This situation can occur when superelastic wires can not reach a plateau, i.e. impossible to produce SIM in clinical levels. B) In this situation SIM formed and the wire could be fitted into the slot bracket. 
there is a lack of characterization of these products. Manufacturers commonly do not specify the real characteristic of the arches.

A lack of reproducibility of the description of properties has been observed. Therefore, many arches available as superelastic do not behave as, others show a very high TTR in which there is crystalline alteration, from the stage where the alloy is totally martensitic until the stage where it is totally austenitic, so that they do not reveal a meaningful effect in the buccal cavity. That happens due to the little difference in temperature between the buccal cavity and the final austenitic temperature of the alloy (temperature gradient) or due to the fact that the wires commercialized present transition temperatures calculated for unstressed situations, consequently not simulating several stress applied situations, such as constant stress conditions in cases of misalignment because of lack of space.

Studies ${ }^{11}$ have shown that at higher the temperature, more difficult it will be for the arches to reach stress induced martensite through applied tension. There are arches whose transition temperature is negative; thus, even before being placed in the mouth, they already show a certain rigidity, so it will be more difficult to insert them totally in the bracket slot, that is, the arches do not reach the martensitic structure, do not form a plateau and an absurd amount of tension would be required, clinically not common, to produce SIM. Arches with such behavior cannot be called superelastic (Fig l).

Researches developed through the calorimetry technique, by means of temperature modulated differential scanning (MDS), have shown that the stages of transformation of Copper $35^{\circ} \mathrm{C}$ NiTi alloys (Ormco, Orange, CA-USA) require an intermediate $\mathrm{R}$ stage; besides, oxide precipitate and density differences are due to the reaction of nickel-titanium with residual oxygen found in the environment. ${ }^{6}$

The literature shows that the classification and understanding of the properties of these alloys become confusing due to the complexity of these phenomena and only studies based on research are capable of determining real effects. Commercially, these alloys are described in a very simplistic way considering their advantages. Researches show that these materials present complex behavior and cannot be examined in an isolated manner.

The first alloy used in Orthodontics, known commercially as Nitinol, did not have the effects of superelasticity, only a discrete shape memory effect, with low rigidity, due to its manufacturing process which produced an alloy with mechanical hardening characteristics (cold work machining that increases the size of grains, altering then the mechanical properties of the material). That is verified by the fact that after removing the arch, after a certain period of use, it was plastically deformed (martensitestabilized in a passive way), if alignment was more severe, these alloys were characterized as being martensite-stabilized and had a very discrete shape memory effect, with temperature increase.

The metallic alloys, in general, might also be studied by examining metal phase transformation diagrams, which reveal the microstructure of the alloys and, as a result, how they will behave concerning their physical properties. Other methods, such as X-rays diffraction (XRD), which allows the study of several crystallographic forms of nickel-titanium $^{31}$ alloys, the differential scanning calorimetry (DSC) ${ }^{5,6}$ technique and the most recent known as temperature modulated differential scanning calorimetry (TMDSC), are effective means to access the stage transformations that are generated after applying tension or torsion upon these alloys; however, diffraction by X-ray reveals itself as more limited for penetrating less than $50 \%{ }^{7}$

Research $^{17}$ using nickel-titanium alloys by means of X-ray diffraction (XRD), with transformation stages at low temperature varying from $-110^{\circ} \mathrm{C}$ to $25^{\circ} \mathrm{C}$, was compared to the results of previous studies ${ }^{7}$ performed using the TMDSC technique. For the study, alloys commercially known as Copper NiTi $35^{\circ} \mathrm{C}$ (Ormco, Orange, CA, USA), Neo Sentalloy (Sentalloy, GAC International, Bohemia, USA) and Nitinol SE (3M Unitek, Monrovia, CA, USA) with transversal section of $0.016 \times 0.022$-in were selected. All the samples studied were superelastic, although the Neo Sentalloy (GAC International), samples are commercialized as having shape memory. A more complete study should take into consideration the complementarity of techniques such as XRD, TMDSC and TEM (transmission electronic microscopy). X-ray diffraction 
(XRD) shows peaks characteristic of the martensitic transformation technique. Thus, non-superelastic alloys are austenitic at room temperature, and that denotes that the martensitic stage is found at very low temperatures. ${ }^{7}$

A study ${ }^{2}$ was performed with shape memory alloys (Cu-Zn-Al) by means of echography and acoustic microscopy in order to observe the crystalline changes in the grain structures step by step. The structures of these alloys $(38,5 \% \mathrm{Zn}$ face crystalline transformation at temperature close to room temperature) have the same chemical constitution, but different crystallographic structure. Martensitic and austenitic structures are cubic of centered body (phase $\beta$ ) and cubic of centered face (phase $\alpha$ ), respectively, and that explains the fact that they do not show the same mechanical behavior. Martensitic structures reveal themselves to be as straight slip bands inside the austenite grains, while austenitic structures show grains with different shades of gray.

A study ${ }^{28}$ performed by means of DSC and electrical resistivity to crystalline transformation in two stages, $\mathrm{NiTi}$ and $\mathrm{NiTiCu}\left(300^{\circ} \mathrm{C}\right.$ to $\left.800^{\circ} \mathrm{C}\right)$ alloys, found that the $\mathrm{R}$ stage is suppressed in NiTi$\mathrm{Cu}$ alloys due to the addition of copper, while NiTi alloys present this intermediate stage from $340^{\circ} \mathrm{C}$ to $410^{\circ} \mathrm{C}$; however, above $410^{\circ} \mathrm{C}$ there was no production of R stage.

The effect of superelasticity was observed in nickel-titanium arches through tension (axial) and stress tests. ${ }^{21}$ Nickel-titanium arches (Chinese NiTi, GAC International, Bohemia, USA) tested by means of stress tests to determine the rigidity, springback and the maximum force of stress, for large activations, showed rigidity of about $7 \%$ compared to the one found in stainless steel, while in activations of little amplitude, rigidity was $28 \%$ in relation to stainless steel. These alloys showed excellent springback capacity, and they might be stressed 1.6 times more than nickel-titanium Nitinol SE (3M, Unitek, Monrovia, CA, USA) alloys. They show a transition temperature a little below mouth temperature, but they are austenitic in this temperature, so they do not reveal effectively the thermoelastic effect, while allowing the production of stress induced martensite.

In three point stress tests with 42 samples of
NiTi alloys of 0.016 -in and $0.016 \times 0.022$-in, which were produced by 9 different manufacturers, we noticed that there was a difference among the samples concerning the stored load with the same transversal section. ${ }^{24}$

The behavior of crystalline transformations, and chemical and topographical compositions of the surfaces of NiTi alloys of different commercial brands, in the shape of rectangular wires $(0.016 \mathrm{x}$ 0.022-in.) such as Neo Sentalloy F80 (Sentalloy, GAC International, Bohemia, USA), Thermo-Active Copper NiTi (A-Company, San Diego, CA, USA; Ormco, Orange, CA, USA), Rematitan LITE (Rematitan 'Lite' nickel titanium, Dentaurum, Germany), Titanol SE S (ForestadentBernhard Förster GmbH, Germany) and Titanal (Lancer Orthodontics Corporation, USA), showed that besides the austenitic and martensitic stages there is a stage called $\mathrm{R}$ phase. The tests were performed within different temperatures $\left(22^{\circ} \mathrm{C}, 37^{\circ} \mathrm{C}\right.$ and $\left.60^{\circ} \mathrm{C}\right)$. The chemical composition and surface analysis tests were performed by means of X-ray spectroscopy, through a scanner attached to an electronic microscope. Regarding the different temperatures analyzed, differential scanning calorimetry (DSC) was used, varying from $-80^{\circ} \mathrm{C}$ to $+80^{\circ} \mathrm{C}$. The mechanical properties were analyzed through three point stress tests. The stress tests showed plateaus during the loading and unloading of tensions. ${ }^{12}$

In recent research ${ }^{19,20}$ the rigidity of nickel-titanium wires during activation and deactivation was observed. It was concluded that if a superelastic alloy is submitted to cold water during its activation phase, the stress force drops and remains at a sub-baseline level until it is once again heated (transient effect). On the other hand, if the alloy is rapidly cooled, during deactivation, the force drops temporarily and the sudden heating induces a transitory increase in the rigidity of the alloy during activation, but with prolonged effect, when heated, during springback (deactivation). The higher the degree of activation (tension) used for activation (dislocation), more springback will become possible during the deactivation phase. The amount of stress required to induce the production of martensite increases as temperature increases from $\mathrm{Ms}$ (initial martensite) to $\mathrm{Md}$ temperature (maximum 
temperature where martensite might still be found), in other words, the higher is the tension (stress) applied, the higher the temperature, so that austenitic transformation becomes possible. ${ }^{20}$

Three point stress tests with NiTi thermoelastic alloys have shown great variability, qualitative and quantitative, performance, since many alloys have remained deformed after the test, and others showed weak or no superelasticity. A study ${ }^{3}$ that involved 48 thermoelastic alloys of transversal sections 0.016-in, $0.016 \times 0.022$-in, $0.017 \times 0.025$-in and $0.018 \times 0.025$-in classified them as true superelastic when the plateau showed deflection $\geq 0,5 \mathrm{~mm}$; superelastic borderline when the plateau showed deflection $<0,5 \mathrm{~mm}$ and $>0,05 \mathrm{~mm}$ and non-superelastic when the plateau showed deflection $\leq 0,05 \mathrm{~mm}$.

The rigidity effect of nickel-titanium alloys was studied concerning the transversal section. Thus, superelastic alloys were used (Ortho-Force, France) with square transversal sections (0.016 $\times 0.016$-in, $0.018 \times 0.018$-in, and $0.020 \times 0.020$-in). The Modulus of Elasticity (E) seems to vary according to the transversal section, but it depends on the amount of martensitic transformation which took place during the phase transformation. An alloy of larger transversal section will not necessarily produce higher forces, meaning that rigidity during stress is not directly related to the transversal section when the superelasticity process takes place..$^{13}$

Torsion tests using superelastic and thermoelastic alloys, aimimg to understand the behavior of alloys under thermal variations and according to different degrees of torsion, have shown that the alloys could not respond to temperature variation and remain at a sub-threshold level when there was a change from a high to a low temperature and then back to a high temperature. They could not regain their resistance to torsion. In some tests (temperature varying from $10^{\circ} \mathrm{C}$ to $80^{\circ} \mathrm{C}$ ) there was a simulation of the thermal changes that take place in the buccal cavity after the ingestion of food. In other torsion tests $\left(25^{\circ}\right)$ superelastic alloys at $18^{\circ} \mathrm{C}, 27^{\circ} \mathrm{C}, 37^{\circ} \mathrm{C}$ and $40^{\circ} \mathrm{C}$ did not show martensitic change, but showed plateaus only in $45^{\circ}$ and $60^{\circ}$ torsions, which would not produce torsion on incisors, since the advocated torsion ranges from $7^{\circ}$ to $22^{\circ} .^{18}$

In another study ${ }^{19}$ involving NiTi superelastic alloys compared to conventional ones and to $\beta$-titanium alloys $0.016 \times 0.022$-in, $0.017 \times 0.025$-in and $0.018 \times 0.025$-in sections and $25^{\circ}$ torsion at $37^{\circ} \mathrm{C}$, it was found a variation in torsion resistance among different alloys and among different manufacturers, and only one alloy tended to superelasticity.

The effect of torsion upon metallic wires of $0.017 \times 0.025$-in and $0.018 \times 0.025$-in transversal sections of different types of alloys commonly used in orthodontics, was studied by means of a device that simulated a dental arch. The wires were inserted in the brackets of a patient simulator. At $15^{\circ}$ activation, Tru-Chrome Stainless Steel 0.017 x 0.025-in wires (RMO, Denver, CO, USA) restored a torsion 4 times stronger than that of a Nitinol SE $0.017 \times 0.025$-in wire (3M Unitek, Monrovia, CA, USA). ${ }^{10}$

Torsion effects have also been examined in laboratory tests aiming evaluate the rigidity of nickeltitanium alloys. Torsion tests have shown that some samples presented curves without plateaus, and that represents lower energy stored due to differences between martensitic transformation temperatures and those simulating buccal cavity ${ }^{15}$ temperatures.

Copper enriched nickel-titanium alloys have shown a decrease in their rigidity and hysteresis, and that would produce a lower moment necessary for activation. However, during deactivation, these alloys could not totally produce the necessary torsion. This paper has demonstrated that in order to select an appropriate superelastic alloy, consideration should be taken not only in the transition temperature, but also rigidity; nevertheless, there is variation between rigidity levels, according to manufacturers and some alloys reveal torsion moments comparable to those of conventional nickel-titanium alloys.

Torsion tests have shown that orthodontic wires whose martensitic phase begins at very low (negative) temperatures depend on a higher unloading torsional moment to form the plateau. In this way, these plateaus would never be reached and, consequently, the wire would behave as a stainless steel wire and the only advantage would be showing a lower modulus of elasticity (E); however, the wire would not reveal any characteristic of superelasticity (formation of plateaus). It has been noticed that the superelasticity effect is influenced by the chemical composition of the nickel-titanium wire (e.g. Ni 
content) as well as by room temperature; thus, if $\mathrm{Ni}$ content is higher, there will be a decrease in temperature for initial martensitic transformation, and a higher force moment would be necessary to induce martensite, meaning that martensite already begins at low temperatures. As a result, at a higher room temperature, there would already be austenitic transformation and greater applied tension would be necessary to produce SIM transformation. ${ }^{11}$

Somsen et $\mathrm{al}^{30}$ studied the effect of thermal treatment on the formation of $\mathrm{R}$ phase, in Ni-rich NiTi alloys, which is related to $\mathrm{Ni}_{4} \mathrm{Ti}_{3}$ precipitates. The effect of electrical resistance in $\mathrm{NiTi}(51 \%<\mathrm{x}<$ $54.5 \%$ ) alloys, $\mathrm{Ni}_{\mathrm{x}} \mathrm{Ti}_{\mathrm{x}-100}$, cooled at several temperatures $\left(\mathrm{T}_{\mathrm{A}}\right)$ and at room temperature, was studied and it was noticed that when the alloys were cooled, at a B2 phase $\left(\mathrm{T}_{\mathrm{A}}=1273 \mathrm{~K}\right)$ of alloys with $51 \%<\mathrm{Ti}<54 \%$, there was an increase in the resistance and there was a decrease below $300 \mathrm{~K}$. Subsequent tempering thermal treatment at $653 \mathrm{~K}$ (lh) and cooling cause the anomalous reduction of electrical resistance below $320 \mathrm{~K}$ and the occurrence of martensitic transformation from $B 2$ to $R$ phase with $T_{R}=310$ $\mathrm{K}$, independent of $\mathrm{x}$. On the other hand, after $723 \mathrm{~K}$ and $823 \mathrm{~K}$ tempering, for 1 hour, there was martensitic transformation in two stages, from B2 to R and subsequently B19' (Ms dependent on $\mathrm{x}$ and $\mathrm{T}_{\mathrm{A}}$ ). After tempering at $923 \mathrm{~K}$ or above, martensitic transition could no longer be found. The first stage, at $500 \mathrm{~K}$, shows structural changes inducing martensitic phases at low temperatures. The second stage, at $900 \mathrm{~K}$, shows the formation of phase B2 and the disappearance of other phases, causing martensitic transition. Thus, NiTi alloys reveal great dependence on instituted thermal treatment as well as on their composition. As a result, they show one or two stages of martensitic transformation, the first stage related to moving from phase B2 to B19' (monoclinic) and the second stage of martensitic transformation from B2 to $\mathrm{R}$ and later to B19'. The R phase is a rhombohedric distortion of the crystalline structure of the B2 towards (111) ${ }_{\mathrm{A}}$.
Compression tests using Instron machine were performed in order to examine the behavior of nickel-titanium coil springs with different geometrical characteristics. The springs were studied at different temperatures $\left(27^{\circ} \mathrm{C}, 37^{\circ} \mathrm{C}\right.$ and $\left.47^{\circ} \mathrm{C}\right)$ and at compression levels varying from $0.5 \mathrm{~N}$ to 3.5 $\mathrm{N}$. The influence of sterilization upon the behavior of $0.016 \times 0.022$-in cross-section wire was examined and the result obtained was that the width of the superelasticity plateaus of different springs moved from $0 \%$ to $66 \%$ of relative compression. The higher is the temperature, the lower is the plateau hysteresis. The temperature increase from $27^{\circ} \mathrm{C}$ to $47^{\circ} \mathrm{C}$, caused an increase in the height and a shortening in the width of the plateaus. There was no meaningful influence of the process of sterilization upon the behavior of springs. In this way, different behavior standards have been established for the different spring configurations. ${ }^{29}$

\section{CONCLUSIONS}

- Nickel-titanium alloys have shown a growing evolution, from the first samples with distinctive martensitic characteristics until the current ones, with thermoelastic and superelastic (pseudoelastic) properties.

- Many nickel-titanium alloys available as superelastic do not correspond to manufacture's specifications being just less stiff than stainless steel alloys.

- The ideal alloy would be one that presented a TTR which coincided with or which would be really close to the temperature of the buccal cavity (Af) in order to allow SIM to be formed; one which did not show a shift of TTR because of the stress applied and would have good springback at room temperature; and which showed a small difference between the plateaus (little hysteresis) and the magnitude between the plateaus would be within tension levels compatible with biological dental movement. 


\section{REFERENCES}

1. Andreasen GF, Hilleman TB. An evaluation of 55 cobalt substituted Nitinol wire for orthodontics. J Am Dent Assoc. 1971 Jun;82(6):1373-5.

2. Augereau F, Despaux G, Gigot V, Leclercq S. An ultrasonic prospecting of shapememory alloy behavior under thermal charges. J Mater Sci. 1998;33(4079-84).

3. Bartzela TN, Senn C, Wichelhaus A. Load-deflection characteristics of superelastic nickel-titanium wires. Angle Orthod. 2007 Nov;77(6):991-8.

4. Barwart $\mathrm{O}$. The effect of temperature change on, the load value of Japanese NiTi coil springs in the superelastic range. Am J Orthod Dentofacial Orthop. 1996 Nov; 110(5):553-8

5. Bradley TG, Brantley WA, Culbertson BM. Differential scanning calorimetry (DSC) analyses of superelastic and nonsuperelastic nickel-titanium orthodontic wires. Am J Orthod Dentofacial Orthop. 1996 Jun;109(6):589-97.

6. Brantley WA, lijima M, Grentzer TH. Temperature modulated DSC provides new insight about nickel-titanium wire transformations. Am J Orthod Dentofacial Orthop. 2003 Oct;124(4):387-94.

7. Brantley WA, Guo W, Clark WA, lijima M. Microestrutural studies of $35^{\circ} \mathrm{C}$ Copper $\mathrm{NiTi}$ orthodontic wire and TEM confirmation of low temperature martensite transformation. Dent Mater. 2008 Feb;24(2):204-10.

8. Buehler WJ, Gilfrich JV, Wiley RC. Effect of low-temperature phase changes on the mechanical properties of alloys near composition NiTi. J Appl Phys. 1963;34:1475-7.

9. Burstone CJ, Qin B, Morton JY. Chinese NiTi wire: a new orthodontic alloy. Am J Orthod. 1985 Jun;87(6):445-52.

10. Filleul MP, Bourgoin G. Comparaison de la rigidité en torsion des fils couramment utilisés en orthodontie. L' 'Orthod Française. 1993;64:107-11.

11. Filleul MP, Constant S. Torsional properties of NiTi orthodontic arch wires. Mater Sci Eng. 1999;A273-275:775-9.

12. Fischer-Brandies H, Es-Souni M, Kock N, Raetzke K, Bock O. Transformation behavior, chemical composition, surface topography and bending properties of five selected 0.016" x 0.022" NiTi archwires. J Orofac Orthop. 2003 Mar;64(2):88-99.

13. Garrec $\mathrm{P}$, Jordan L. Stiffness in bending of a superelastic Ni-Ti orthodontic wire as a function of cross-sectional dimension. Angle Orthod. 2004 Oct;74(5):691-6.

14. Grimm MJ. Orthopedic biomaterials. In: Kutz M, editor. Standard Handbook of Biomedical Engineering and Design. New York (NY): McGraw Hill Handbooks; 2004. p. 15.1-15.22.

15. Gurgel J de A, Kerr S, Powers JM, Pinzan A. Torsional properties of commercial nickel-titanium wires during activation and deactivation. Am J Orthod Dentofacial Orthop. 2001 Jul;120(1):76-9.

16. Gurgel JA, Kerr S, Powers JM, LeCrone V. Force-deflection properties of superelastic nickel-titanium archwires. Am J Orthod Dentofacial Orthop. 2001 Oct;120(4):378-82.
17. lijima M, Brantley WA, Guo WH, Clark WA, Yuasa T, Mizoguchi I. X- ray diffraction study of low temperature phase transformation in nickel-titanium orthodontic wires. Dent Mater. 2008 Nov;24(11):1454-60.

18. Meling TR, Odegaard J. The effect of the short-term temperature changes on the mechanical properties of rectangular nickel titanium arch wires tested in torsion. Angle Orthod. 1998 Aug;68(4):369-76.

19. Meling TR, Odegaard J. The effect of temperature on the elastic responses to longitudinal of rectangular nickel titanium archwires. Angle Orthod. 1998 Aug;68(4):357-68.

20. Meling TR, Odegaard J. On the variability of cross-sectional dimensions and torsional properties of rectangular nickel-titanium archwires. Am J Orthod Dentofacial Orthop. 1998 May;113(5):546-57.

21. Miura F, Mogi M, Ohura Y, Hamanaka $H$. The superelastic properties of the Japanese NiTi alloy wire for use in orthodontics. Am J Orthod Dentofacial Orthop. 1986 Jul; $90(1): 1-10$

22. Moiseev VN. Titanium in Russia. Metal Sci Heat Treat. 2005;47:23-9.

23. Muraviev SE, Ospanova GB, Shlyakhova MY. Estimation of force produced by nickel-titanium superelastic archwires at large deflections. Am J Orthod Dentofacial Orthop. 2001 Jun;119(6):604-9.

24. Nakano H, Satoh K, Norris R, Jin T, Kamegai T, Ishikawa F, et al. Mechanical properties of several nickel-titanium alloy wires in three-point bending tests. Am J Orthod Dentofacial Orthop. 1999 Apr;115(4):390-5

25. Parvizi F, Rock WP. The load/deflection characteristics of thermally activated orthodontic archwires. Eur J Orthod. 2003 Aug;25(4):417-21.

26. Santoro M, Nicolay OF, Cangialosi TJ. Pseudoelasticity and thermoelasticity of nickel-titanium alloys: A clinically oriented review. Part I: Temperature transitional ranges. Am J Orthod Dentofacial Orthop. 2001 Jun;119(6):587-93.

27. Santoro M, Beshers DN. Nickel-titanium alloys: Stress-related temperature transitional range. Am J Orthod Dentofacial Orthop. 2000 Dec;118(6):685-92.

28. Uchil J, Mahesh KK, Ganesh KK. Dilatometric study of martensitic transformation in NiTiCu and NiTi shape memory alloys. J Mater Sci. 2001;36(24):5823-7.

29. Schneevoigt R, Haase A, Eckardt VL, Harzer W, Bourauel C. Laboratory analysis of superelastic NiTi compression springs. Med Eng Phys. 1999 Mar;21(2):119-25.

30. Somsen $\mathrm{CH}$, Zähres H, Kästner J, Wassermann EF, Kakeshita T, Saburi T. Influence of thermal annealing on the martensitic transitions in $\mathrm{Ni}$-Ti shape memory alloys. Mater Sci Eng. 1999:273-275(1-2):310-4. 